\title{
Ensinando programação em Ambientes Escolares por meio da linguagem Python
}

João Pedro Pereira de Cerqueira Cardoso ${ }^{1}$, Carlos Alberto Rodrigues ${ }^{2}$

1. Bolsista PIBIC/CNPq, Graduando em Engenharia da Computação, Universidade

Estadual de Feira de Santana,

e-mail: pedroecomp@gmail.com

2. Orientador, Departamento de Ciências Exatas (DEXA), Universidade Estadual de

Feira de Santana,

e-mail: carlos.fsa@gmail.com

PALAVRAS-CHAVE: Aprendizagem, programação, ambientes lúdicos, AppInventor

\section{INTRODUÇÃO}

Aprender a programar é uma tarefa que demanda tempo, paciência e atenção, pois é preciso entender conceitos mais gerais como raciocínio lógico, álgebra, conceitos mais específicos como estrutura de dados, projeto de algoritmos, sintaxe e semântica das linguagens de programação.

Além desse fatores, a falta de uma interação rápida da linguagem com o aluno, mesmo com pouco conhecimento sobre a mesma, desestimula o interesse e faz muitos desistirem de começarem a buscar mais conhecimento na área. Estima-se que num futuro próximo haja um déficit muito grande de profissionais na área de tecnologia de informação(TI), (Brasscom, 2012).

Para que houvesse um primeiro contato com programação envolvendo alunos de ensino médio e com os ingressantes do curso de Engenharia de Computação, foi organizado um curso de programação baseado em jogos na linguagem Python, pois segundo Marques, os jogos constituem um fator motivador para o aumento do interesse dos alunos pela área da Computação, (Marques et al., 2011),.

Alguns autores constatam que o Python é uma boa linguagem para introduzir programação para novatos devido a sua facilidade de aprendizado, sintaxe simples, reforço de estrutura, dentre outros fatores, (Ceder \& Yergler, 2003; Grandell et al., 2006) e por este motivo essa linguagem foi utilizada.

Como auxílio neste processo, foi adotada a ferramenta APPINVENTOR (Wolber, 2011; Abelson et al., 2012) que é uma ferramenta a qual pode-se desenvolver aplicativos para smartphones com o sistema Android com poucos passos, através da junção de blocos como num jogo de lego. Sabendo disso foram propostas oficinas utilizando a metodologia PBL (Problem-Based Learning), (Barrows \& Tamblyn, 1980) , na qual os grupos deveriam desenvolver seus aplicativos, utilizando esta ferramenta.

Além dessas ferramentas para melhorar o aprendizado, utilizamos outras como Greenfoot, BlueJ, Robocode e Scratch para aperfeiçoar o nosso ensino e identificar possíveis problemas e dificuldades das oficinas e dos alunos. Essas atividades foram feitas por meio de observações, questionários e entrevistas pós oficina. 


\section{METODOLOGIA}

O objetivo deste trabalho envolve trabalhar com alunos do ensino médio, mas o trabalho acabou sendo focado também para alunos do curso de graduação, com o objetivo de reter os mesmos nos cursos da área da Computação e produzir material didático, aplicando um metodologia mais prática e motivadora. Essa ampliação ocorreu devido a falta de oportunidades encontradas em colégios pela carência de laboratórios.

O Scratch já foi utilizado como ferramenta de apoio ao ensino de uma disciplina introdutória de programação na Universidade de Harvard e foi encarada como uma experiência positiva para o aprendizado de alunos iniciantes na disciplina (Leiner, 2007). Esta ferramenta é um ambiente lúdico no qual através de junção de blocos os estudantes podem desenvolver jogos.

Outra ferramenta é o Robocode, no qual é possível programar robôs em Java, e através desta ferramenta é possível ensinar conceitos de sintaxe e de POO (Amaral, 2015). Outra ferramenta auxiliar para ensino deste tipo de linguagem é o Greenfoot que é um ambiente voltado especificamente para facilitar a aprendizagem de POO (Kolling, 2010).

Utilizando estas ferramentas, foram realizadas 6(seis) oficinas, as quais foram realizadas para escolas técnicas, ensino médio e graduação.

Analisando todos estes dados, a ideia era realizar oficinas com participação ativa dos alunos, com ferramentas lúdicas e motivadoras, tendo como objetivo aumentar o interesse na área da Computação e diminuir as dificuldades encontradas nas disciplinas iniciais, quando aplicamos a mesma em cursos de nível superior e técnicos.

Além disto, foram realizadas algumas oficinas com público alvo em estudantes de ensino médio. Estas oficinas tinham a mesma metodologia aplicada no curso de graduação, mas como o tempo era menor, então foi necessário fazer algumas adaptações para que fosse acessível aos estudantes.

Para a análise dos dados foram coletadas observações e aplicados questionários. Estas foram escritas por um observador que não participando ativamente da oficina, analisava o comportamento e reações dos alunos ao longo das aulas.

\section{RESULTADOS}

Ao longo do período vigente da bolsa, foram realizadas o maior número possível de oficinas possíveis, sempre visando incentivar da melhor forma os alunos a terem mais interesse na área da Computação. Por este trabalho ser uma continuação do trabalho anterior, já havia muitas competências necessárias para execução das oficinas. A seguir serão descritas as oficinas realizadas:

\section{Oficinas no curso de Engenharia de Computação ( Scratch e POO )}

As oficinas que foram realizadas no curso de Engenharia de Computação ocorreram na semana anterior ao início do semestre letivo 2015.2, para evitar problemas de choques de horários e assim contarmos com a participação de um público maior. Porém, isso acarretou em um público menor, pois muitos alunos (calouros e veteranos) 
preferem aproveitar o período como férias. Estas observações já foram percebidas em trabalhos anteriores e já eram esperadas.

Um dos fatores que melhorou o aproveitamento dos alunos para esta oficina é, que diferente dos alunos de escola, estes tem uma maturidade mais elevada, estão muito mais motivados a aprender e como a ferramenta que tem ênfase na área que eles escolheram, eles estão muito mais aptos a conseguir as competências almejáveis para os participantes deste tipo de oficina.

\section{2) Oficinas IFBAIANO - Campus Governador Mangabeira}

Esta oficina foi a continuação de um trabalho feito anteriormente, mas desta vez os alunos participantes foram alunos do $1^{\circ}$ ano. No geral foi aplicada a mesma metodologia mas nesta oficina foi trocado o ultimo desafio para os alunos, pois da última vez desenvolveram o jogo da velha, mas desta vez foi feito o jogo snake. A oficina baseava-se na linguagem de Programação Python e uma biblioteca de módulos gráficos para jogos Pygame. As oficinas foram realizadas nos turnos matutino e vespertino em dois dias, totalizando 12 horas, sendo 3 horas em cada turno.

\section{3) Oficina IFBA - Feira de Santana}

Também houve pouco publico nesta oficina. Apesar disto, os alunos presentes eram participativos, queriam entender mais sobre a linguagem e a ferramenta e interessados na área da Computação como área a qual desejam seguir carreira.

\section{4) App inventor em Engenharia de Computação}

Apesar de não constar no objetivo do trabalho, foi realizada uma oficina de App Inventor e esta foi aplicada com os alunos calouros do curso de Engenharia de Computação. Esta oficina tinha como foco diminuir o choque dos alunos com a nova metodologia de ensino que iriam ter que lidar ao longo do curso. Para isso a oficina funcionou utilizando a metodologia PBL, a mesma que já é utilizada no curso e divididos em 4 turmas. os alunos foram apresentados a metodologia e ao mesmo tempo utilizando a ferramenta, conseguiram desenvolver uma aplicação para a plataforma Android.

\section{5) Introdução a Ciência da Computação em Engenharia Civil}

A proposta dessa disciplina era realizar um piloto de como utilizar ferramentas mais lúdicas. Neste caso foram escolhidas Scratch, AppInventor e Python para uma disciplina tradicional de Introdução à Ciência da Computação (ICC). A ideia dos alunos era de que a matéria era "chata", muitas vezes enraizada pelos veteranos. Inclusive haviam alunos veteranos na turma, onde um destes chegou a falar "se a matéria fosse sempre assim eu teria aprendido mais e tinha passado". A disciplina foi dividida em três 
unidades, com 20 horas por unidade, e em cada uma foi trabalhada com uma ferramenta diferente. Na primeira unidade foi utilizada a ferramenta Scratch e os alunos tiveram bastante facilidade na utilização da mesma. As aulas teóricas eram a base do que eles teriam que fazer na prática e isso facilitou bastante, além da ferramenta ser bastante intuitiva. Era esperado uma boa maturidade dos estudantes mas também um interesse não muito grande, já que além do histórico ruim da disciplina os próprios conteúdos não eram da área de interesse deles. Apesar disto notou-se um interesse crescente ao longo das aulas, pois os alunos cada vez mais participavam questionando ou auxiliando o professor no desenvolvimento das atividades.

Na tabela 1, temos os resultados dos números de alunos alcançados por oficina ministrada.

Tabela 1. Alunos alcançados

\begin{tabular}{|l|l|}
\hline Oficina & Quantidade de alunos alcançados \\
\hline 1) Oficina de POO em Engenharia de Computação & 21 alunos \\
\hline 2) Oficina de Python IFBaiano & 8 alunos \\
\hline 2) Oficina de Python IFBaiano & 13 alunos \\
\hline 3) Oficina Python IFBA Feira de Santana & 5 alunos \\
\hline 4)Oficina de App Inventor em Engenharia da Computação & 30 alunos \\
\hline 5) Introdução à Ciência da Computação & 40 alunos \\
\hline
\end{tabular}

Sobre a quantidade de alunos alcançados, existem alguns fatores extra oficina que podemos citar, obtidos através das observações:

- Oficinas obrigatórias : Algumas oficinas foram obrigatórias para os alunos, e por causa disto alguns alunos estavam bastante desinteressados, conversavam e atrapalhavam a oficina.

- Pré-Semestre : Algumas oficinas ocorreram antes do inicio do semestre letivo e muitos dos alunos potenciais, preferiram ficar mais tempo em casa, ou viajando, do que vir para as oficinas.

- Diurno : Na oportunidade da oficina do IFBA, os alunos teriam que se deslocar para o IFBA no turno oposto a suas aulas, o que consequentemente faria com que os alunos passassem o dia todo na instituição. Muitos alunos que se mostraram motivados no dia da inscrição, acabaram abrindo mão de ir para a oficina por causa desta condição.

\section{CONSIDERAÇÕES FINAIS}

Ao final deste trabalho notou-se que apesar do foco maior na disciplina de ICC em outro publico alvo, foram alcançados bons resultados com outros públicos. Pois além de produzir material didático, as oficinas foram bastante produtivas, tanto para o conhecimento teórico dos alunos, quanto prático para os professores e monitores e apesar do número reduzido de participantes em algumas delas, foram observados resultados bastante enriquecedores tanto do ponto de vista técnico e prático. Isto ocorreu visto que foram produzidos materiais que podem facilmente ser aplicados em outras oficinas e disciplinas, e tanto os participantes, monitores e professores, tiverem 
uma experiência nova em diversos aspectos como tempo de oficina, metodologia de avaliação e teste de ferramentas.

\section{REFERÊNCIAS}

ABELSON, H.; MORELLI, R.; TURBAK, F., 2012. Teaching CS0 with Mobile Apps Using App Inventor. Journal of Computing Sciences in Colleges, v. 27, n. 6, p. 16-18.

AMARAL, L. R. et al., 2015. Plataforma Robocode como Ferramenta Lúdica de Ensino de Programação de Computadores - Extensão Universitária em Escolas Publicas de Minas Gerais.

BARROWS, H. S.; TAMBLYN, R. M. 1980. Problem based-learning: An approach to medical education. [s.1.] Springer Publishing Company, v. 1.

CEDER, V.; YERGLER, 2003. N. Teaching Programming with Python and PyGame Python in our Introduction to Computer classPyCon 2003 - Python Conference.

GRANDELL, L. et al., 2006. Why Complicate Things? Introducing Programming in High School using Python. ACE '06 Proceedings of the 8th Australasian Conference on Computing Education.

MALAN, D. J.; LEITNER, H. H. 2007. Scratch for budding computer scientists. Proceedings do 38th SIGCSE'07, Kentucky, USA, p. 223-227.

MARQUES, D. L. et al., 2011. Atraindo Alunos do Ensino Médio para a Computação: Uma Experiência Prática de Introdução a Programação utilizando Jogos e Python. Anais do XXII Simpósio Brasileiro de Informática na Educação.

WOLBER, D. 2011. App Inventor and Real-world Motivation Proceedings of the 42o ACM Technical Symposium on Computer Science Education. SIGCSE '11.New York, NY, USA: ACM. 